\title{
Pattern of accidents and injuries involving three-wheelers
}

\author{
Mohan de Silva', LP Nellihala ${ }^{2}$ and Dayasiri Fernando ${ }^{3}$ \\ (Index words: Breaking the handle-lock, alcohol consumption, long bone fracture, case fatality).
}

\begin{abstract}
Objective To study the pattern of injuries and some causative factors of three-wheeler related accidents.

Design Prospective descriptive study.

Setting Accident unit, Colombo South Teaching Hospital, Kalubowila.
\end{abstract}

Methods One hundred patients admitted to Colombo South Teaching Hospital with three-wheeler related accidents were interviewed, examined within 24 hours of admission and followed up by using a standard questionnaire. Detailed descriptions of the accident and the types of injuries were recorded.

Results 54 accidents took place during daytime $07.00 \mathrm{~h}$ to $19.00 \mathrm{~h}$ ) and the passengers were the commonest victims (40\%). Soft tissue injury was the commonest injury observed (75\%). The second commonest type of injurity was long bone fractures $(21 \%)$. Toppling due to a sudden turn of the vehicle accounted for $30 \%$ of accidents. Of 28 drivers in the study group, 25 admitted breaking the handlelock to increase the vehicle's tuming angle. Toppling due to a sudden turn was identified as the cause of the accident in all those who had interfered with the handle-lock. At the time of the accident, $89 \%$ of the drivers and $28.1 \%$ of pedestrians were under the influence of alcohol. Alcohol was related to $67.4 \%$ of the night accidents.

Conclusions Alcohol consumption was recognised as a major contributory factor, in particular for night accidents. A strong association was observed between mechanical alteration of the vehicle's handle-lock and the risk of accident. Introduction of legislation to prohibit handle-lock alteration and strict implementation of the law regarding driving under the influence of alcohol would help to reduce three-wheeler related accidents.

\section{Introduction}

Autoriksha, commonly known as a three wheelers (1), is fast becoming one of the most popular modes of transport in Sri Lanka. Up to 1998, the Department of Motor Traffic had registered 75666 three-wheelers. Being a smaller and lighter vehicle, which is relatively open, they are more prone to accidents than motor cars. The vehicle is relatively cheap and has become a popular form of selfemployment. Frequency of three-wheeler related accidents seen at the accident unit of Colombo South Teaching Hospital prompted us to initiate this study.

\section{Methods}

All patients admitted to the accident unit at Colombo South Teaching Hospital following three-wheeler related accidents from 1 May 1998 for a period of six months were included in the study. Patients who had taken only outpatient treatment were excluded, but the deaths brought to the hospital following three-wheeler related accidents were included. All patients who were in a stable condition were interviewed, examined and followed up by us within 24 hours of admission. A structured questionnaire was used after pre-testing for validation. Informed consent was obtained. During the pre-testing stage the practice of breaking the handle-lock to increase the turning angle of the vehicle came to our notice.

\section{Results}

Fifty four percent of accidents took place during daytime $(07.00 \mathrm{~h}$ to $19.00 \mathrm{~h})$, and of the night accidents, $67.4 \%$ were found to be alcohol related. As shown in Table 160 victims were below the age of 30 years, of whom $83 \%$ were males. In the over 30 years age group, $76 \%$ were males.

Table 1. Age and sex distribution of three-wheeler accident victims

$\begin{array}{ll}\text { Age (Years) } & \% \\ 0-10 & 5 \% \\ 11-20 & 18 \% \\ 21-30 & 37 \% \\ 31-40 & 20 \% \\ 41-50 & 10 \% \\ 51-60 & 6 \% \\ 61-70 & 4 \% \\ <30 & 60(83 \% \text { males }) \\ >30 & 40(76 \% \text { males })\end{array}$

Soft tissue injury was the commonest injury identified $(n=59)$. Of the 35 victims who were kept under observation for head injury, only 5 had a neurological deficit (14.2\%), but none had abnormal CT findings. Of the 21 long bone fractures, $80.9 \%$ involved lower limbs. There were 8 thoracic injuries. Apart from the two deaths that were brought to the hospital following major three-wheeler accidents, only one other patient had a life-threatening injury. This patient had haemoperitoneum following a toppling accident, and had nephrectomy for a ruptured kidney.

${ }^{1}$ Senior lecturer, ${ }^{2}$ Registrar, ${ }^{3}$ Professor, Department of Surgery, Faculty of Medical Sciences, University of Sri Jayawardenepura, Nugegoda. (Revised version accepted 16 December 2000) 
There were 40 passengers, 32 pedestrians and 28 drivers among the victims. At the time of admission, $34 \mathrm{pa}-$ tients ( 25 drivers and 9 pedestrians) were under the influence of alcohol. Of drivers, $89.2 \%$ were under the inflkuence of alcohol. None of the passangers were under the influence of alcohol. Most of the victims (64.7\%) who were involved in night accidents had consumed alcohol.

The first event that had caused the accident was taken as the main reason for it. Events were classified into four groups (Table 2) Toppling due to a sudden turn was recognised as the second commonest cause of threewheeler. Of the 30 victims of vehicle toppling, 25 were drivers who admitted interfering with the handle-lock. The other 5 victims were passengers in these vehicles. Hence handlelock interference can be considered as one of the main reasons for three-wheeler toppling accidents.

The turning circle of a three-wheeler is $576 \mathrm{~cm}$. This is controlled by a handle-lock, which is a protrusion from the handle bar that restricts the turning angle of the handle. Removal of this device increases the turning angle of the handle. Discussions with many three-wheeler drivers in the city indicated that this practice is very common.

Table 2. Causes of accidents involving three-wheelers

\section{Event}

Number

Toppling due to sudden turn

Hit by another vehicle

Ran over a static object

Knocked down by a three-wheeler

\section{Discussion}

Sri Lanka Police department statistics for the year 1998 indicate that there were $99(1.8 \%)$ fatal accidents among 5535 three-wheeler accidents (2). Although there were 15 207 motor car accidents during the same year, the case fatality rate was only $0.78 \%$. In our study the case fatality rate for three-wheeler accidents was $2.0 \%$.

Soft tissue injuries (59\%) were the commonest type of injury observed in our study. Though there were 35 head injuries, none needed emergency neurosurgical intervention. No spinal injuries were seen in this series, in contrast to high-speed automobile accidents (3). However, 21 long bone fractures constituted a significant morbidity in terms of long hospital stay and economic loss to the family.

Although it is not possible to recognise specific contributory factors for an automobile accident withcut an analytical study, we wish to highlight two important factors that were found in our study. The most significant finding of this study was the unauthorised alteration of the handle-lock, which contributed to toppling of the vehicle. Alcohol consumption was also identified as an important factor, in particular for night accidents.

Based on the findings of this study we recommend heavy penalties for driving after consuming alcohol and legislation to prevent unauthorised alterations to the turning angle of three-wheelers.

\section{References}

1. Department of Motor Traffic Annual Report, 1998.

2. Sri Lanka Police Annual Report - road traffic accidents, 1998.

3. Stanislas MJ, Latham JM, Porter KM, Alper EK, Stirling AJ. A high risk group for thoracolumbar fractures. Injury 1998; 29: 15-8. 